\title{
Importancia de la implementación de la tomografía de tórax para coadyuvar al diagnóstico precoz y triaje oportuno de pacientes con la COVID-19 en hospitales del Perú
} Importance of the implementation of the chest tomography
to contribute to the early diagnosis and timely triage of
patients with COVID-19 in Peruvian hospitals

Correspondencia Juan J. Pareja Ramos Juan_josepr2011@hotmail.com

Recibido: $21 / 04 / 2020$ Aprobado: 11/06/2020

Citar como: Pareja-Ramos IJ, Anicama SE, PerezUrrutia P, Pecho-Silva S, Amado J. Importancia de la implementación de la tomografía de tórax para coadyuvar al diagnóstico precoz $y$ triaje oportuno de pacientes con la COVID-19 en hospitales del Perú. Acta Med Peru. 2020;37(2):239-41. doi: https://doi.org/10.35663/ amp.2020.372.946
Juan J. Pareja-Ramos 1,2,a, Sue E. Anicama,3,a, Percy Perez-Urrutia 1,3,b, Samuel Pecho-Silva ${ }^{4,5, c}$, José Amado $2,6, b, d$

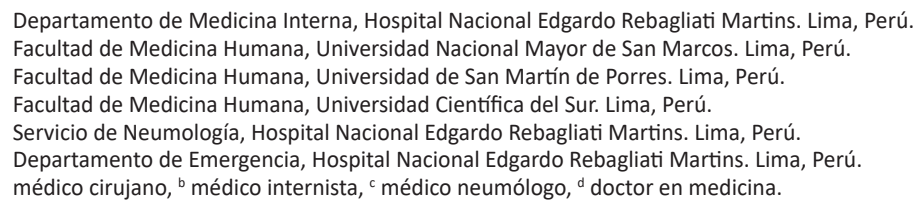

Sr. Editor,

En el Perú, en el contexto de la pandemia de enfermedad por coronavirus 2019 (COVID-19), un gran número de pacientes contagiados son evaluados en los servicios de emergencia de los diferentes hospitales del país. En ese sentido, es vital que se realice un diagnóstico precoz de la enfermedad con el fin de identificar inmediatamente a los pacientes de alto riesgo que necesitarán ser ingresados a diversas áreas críticas y para realizar un correcto triaje de los pacientes afectados por otras enfermedades agudas.

Si bien es cierto que la prueba de referencia para el diagnóstico de la enfermedad es la técnica de reacción en cadena de la polimerasa en tiempo real (RT-PCR), en nuestro medio, su resultado demora entre cuatro y cinco días, retrasando un diagnóstico oportuno. Además, se ha identificado, en la práctica clínica, que la RT-PCR presenta una alta frecuencia de falsos negativos que, dependiendo del tiempo de enfermedad, puede variar del $38 \%$ al $66 \%$, lo cual provocaría un triaje inadecuado y un diagnóstico tardío de los enfermos, exponiendo a otros pacientes sin la enfermedad y a la población sana a un potencial contagio ${ }^{[1,2]}$.

El rendimiento diagnóstico de la RT-PCR no es el mejor ${ }^{[3]}$. Wang et al. ${ }^{[4]}$ evaluaron, mediante la RTPCR, a 1070 muestras provenientes de 205 pacientes con COVID-19 confirmado y encontraron un resultado positivo en el $63 \%$ de las muestras provenientes de hisopado nasal y en el $32 \%$ de las de hisopado faríngeo. Estos hallazgos son semejantes a lo reportado por Ai et al. ${ }^{[5]}$, quienes evaluaron a 1014 pacientes hospitalizados con sospecha de COVID-19 y en los que la prueba RT-PCR inicial resulto positiva solo en el 59\%. Asimismo, Vidal-Anzardo et al. ${ }^{[6]}$ observaron un bajo rendimiento diagnóstico de la RT-PCR, el cual se debería a problemas con la calidad de la muestra, el transporte o hasta con la técnica de procesamiento.

En este sentido, la tomografía computarizada de tórax (TCT) asumiría un rol importante para coadyuvar al diagnóstico precoz y evaluar la extensión del compromiso pulmonar en pacientes hospitalizados con enfermedad moderada a severa. En la serie retrospectiva de Ai et al. ${ }^{[5]}$, las tasas de positividad de la 


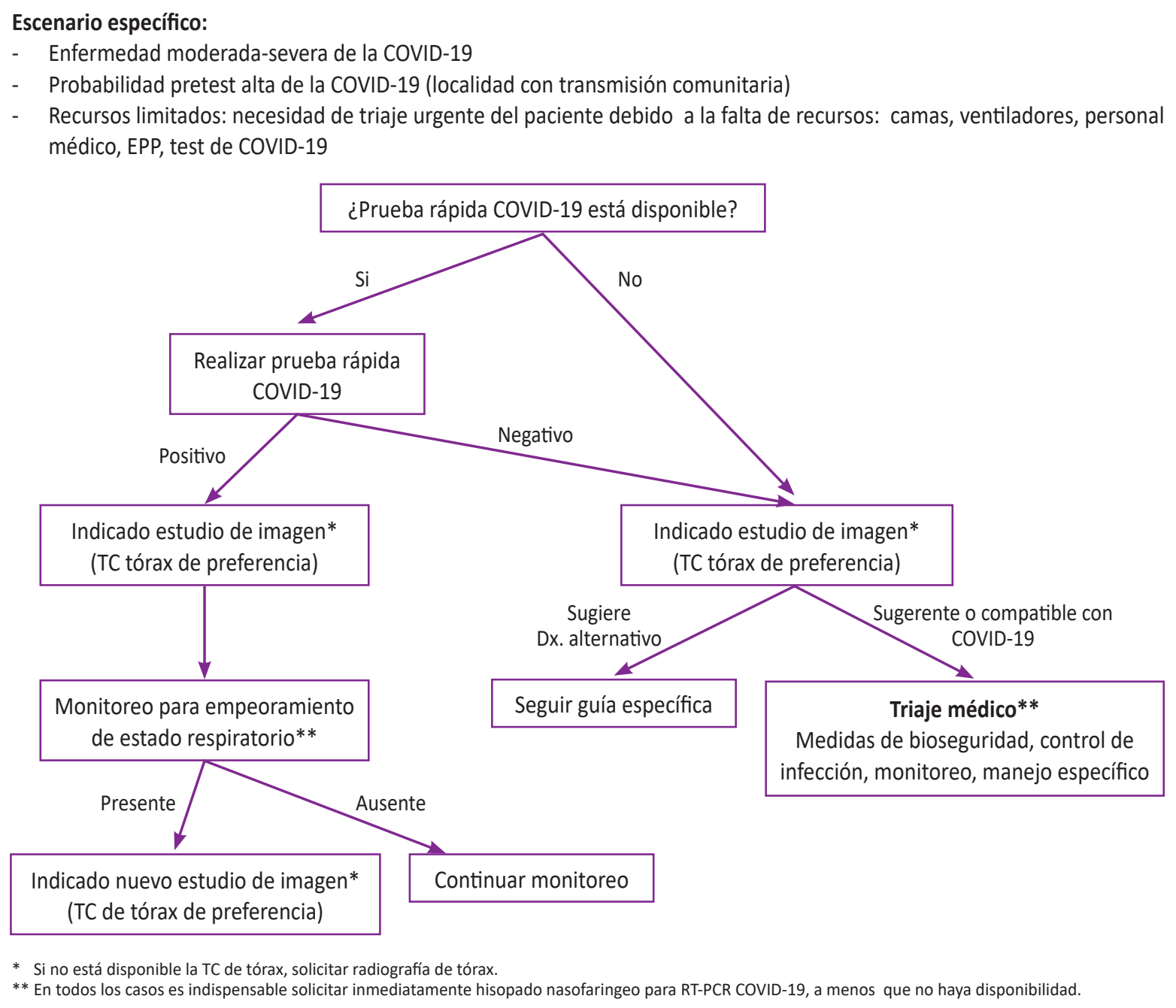

Adaptado de The role of chest imaging in patient management during the COVID-19 Pandemic: A Multinational Consensus Statement from the Fleischner Society ${ }^{[12]}$. TC: tomografía computarizada; Dx: diagnóstico

Figura 1. Algoritmo diagnóstico propuesto para pacientes con sospecha de la COVID-19.

RT-PCR y la TCT fueron de 59\% (601/1014) y 88\% (888/1014) respectivamente; con la RT-PCR como referencia, la sensibilidad de la TCT llegó hasta el 97\% (580/601). Por su parte el estudio de Yang et al. ${ }^{[7]}$ evaluó el valor de la puntuación de gravedad de la TCT en la diferenciación de formas clínicas de COVID-19 y encontró una sensibilidad del $83,3 \%$ y una especificidad del $94 \%$ para identificar pacientes graves. Asimismo, en el estudio de Yuan et al. ${ }^{[8]}$ se elaboró un sistema de puntuación pronóstica, aún no aceptada ampliamente, para estratificar a los pacientes; la mortalidad fue mayor en aquellos con puntuaciones altas.

Recientemente se publicó el estudio de Buyun Xu et al. ${ }^{[9]}$, un revisión sistemática y metaanálisis de 16 estudios de precisión diagnóstica de la TCT para detectar la COVID-19; encontraron que la sensibilidad agrupada fue del 92\% (IC 95\%: 86 - 96\%) y concluyeron que la TCT es un método rápido, conveniente y efectivo para reconocer de forma temprana los casos sospechosos sobre todo en un medio de alta carga de enfermedad. El estudio en preimpresión de De Smet et al. ${ }^{[10]}$, una cohorte prospectiva de 1997 pacientes, encontró que la puntación tomográfica CO-RADS tuvo un poder diagnóstico significativo en pacientes sintomáticos con un $89,1 \%$ de sensibilidad y un $72,5 \%$ de especificidad.

Aunque el Colegio Americano de Radiología ${ }^{[11]}$ ha recomendado no realizar TCT de rutina para identificar a la enfermedad, puesto que los hallazgos no son específicos y se superponen con otras infecciones, el consenso multinacional e interdisciplinario publicado por Rubin et al. ${ }^{[12]}$ emite recomendaciones que serían más afines con nuestra realidad, un escenario en donde los recursos son limitados, con alta carga de transmisión comunitaria y por ende una alta probabilidad pretest; los autores proponen que los estudios de imagen están recomendados para aquellos pacientes con características clínicas de enfermedad moderada o severa compatibles con COVID-19, para ayudar a su triaje oportuno y a la rápida toma de decisiones (Ver propuesta de algoritmo en Figura 1). 
Durante esta coyuntura, no se conoce con certeza si los hospitales de referencia del país cuentan con un tomógrafo operativo en las áreas donde se admiten pacientes con sospecha o diagnóstico de la COVID-19. El informe de la Defensoría del Pueblo del año $2016^{[13]}$ indicó que el $42 \%(n=38)$ de los servicios de emergencia a nivel nacional contaban con un equipo de tomografía, la mayoría de ellos en hospitales de referencia. En este sentido se sugiere a las autoridades de salud que en las instituciones que cuenten con tomógrafo, se garantice su implementación para ayuda diagnóstica de la COVID-19, respetando las medidas de bioseguridad, aprovechando su rendimiento diagnóstico, su valor pronóstico, la rapidez de su realización y que no es necesario el uso de contraste endovenoso, todo ello aunado al correcto proceso de diagnóstico clínico.

Fuentes de financiamiento: autofinanciado.

Contribuciones de autoría: JJPR, SEAS, PPU, SPS y JA contribuyeron en la concepción, diseño y redacción del presente manuscrito. Todos los autores dieron su aprobación a la versión enviada para publicación.

Potenciales conflictos de interés: todos los autores declaran que no tienen conflictos de interés

\section{ORCID}

Juan J. Pareja-Ramos, https://orcid.org/0000-0001-7082-0117 Sue E. Anicama-Silva, https://orcid.org/0000-0002-0241-5993 Percy Perez-Urrutia, https://orcid.org/0000-0001-9388-6012 Samuel Pecho-Silva, https://orcid.org/0000-0002-7477-9841 José Amado, https://orcid.org/0000-0002-3286-4650

\section{REFERENCIAS BIBLIOGRÁFICAS}

1. Kucirka LM, Lauer SA, Laeyendecker O, Boon D, Lessler J. Variation in false-negative rate of reverse transcriptase polymerase chain reaction-based SARS-CoV-2 tests by time since exposure. Ann of Intern Med. 2020;M20-1495. doi: 10.7326/M20-1495.

2. Woloshin S, Patel N, Kesselheim AS. False negative tests for SARSCoV-2 infection - challenges and implications. N Eng J Med. 2020 Jun 5. doi: 10.1056/NEJMp2015897.
3. Fang $\mathrm{Y}$, Zhang $\mathrm{H}$, Xie J, Lin $\mathrm{M}$, Ying $L$, Pang $P$, et al. Sensitivity of chest CT for COVID-19: comparison to RT-PCR. Radiology. 2020 Feb 19;200432. doi: 10.1148/radiol.2020200432.

4. Wang W, Xu Y, Gao R, Lu R, Han K, Wu G, et al. Detection of SARS-CoV-2 in different types of clinical specimens. JAMA. 2020;323(18):1843-4. doi: 10.1001/jama.2020.3786.

5. Ai T, Yang Z, Hou H, Zhan C, Chen C, Lv W, et al. Correlation of chest CT and RT-PCR testing in coronavirus disease 2019 (COVID-19) in China: a report of 1014 cases. Radiology. 2020 Feb 26;200642. doi: 10.1148/radiol.2020200642.

6. Vidal-Anzardo M, Solis G, Solari L, Minaya G, Ayala-Quintanilla B, Astete-Cornejo J, et al. Evaluación en condiciones de campo de una prueba rápida para detección de anticuerpos $\operatorname{lgM}$ e IgG contra SARS-CoV-2. Rev Peru Med Exp Salud Pública. 2020;37(2):203-9. doi: 10.17843/rpmesp.2020.372.5534.

7. Yang R, Li X, Liu H, Zhen Y, Zhang X, Xiong $Q$, et al. Chest CT severity score: an imaging tool for assessing severe COVID-19. Radiol Cardiothorac Imaging. 2020;2(2):e200047. doi: 10.1148/ ryct.2019180009.

8. Yuan M, Yin W, Tao Z, Tan W, Hu Y. Association of radiologic findings with mortality of patients infected with 2019 novel coronavirus in Wuhan, China. PLOS ONE. 2020;15(3):e0230548. doi: 10.1371/ journal.pone.0230548.

9. Xu B, Xing Y, Peng J, Zheng Z, Tang W, Sun Y, et al. Chest CT for detecting COVID-19: a systematic review and meta-analysis of diagnostic accuracy. Eur Radiol. 2020;1-8. doi: 10.1007/s00330020-06934-2.

10. De Smet K, De Smet D, Demedts I, Bouckaert B, Ryckaert T, Laridon $E$, et al. Diagnostic power of chest CT for COVID-19: to screen or not to screen [Internet]. medRxiv; 2020 May [citado 02 junio 2020]. Disponible en: http://medrxiv.org/lookup/doi/10.1101/2020.05.1 8.20097444 .

11. American College of Radiology. ACR recommendations for the use of chest radiography and computed tomography (CT) for suspected COVID-19 infection [internet]. Virginia: ACR; 22 marzo 2020 [citado 20 abril 2020]. Disponible en: https://www.acr.org/Advocacy-andEconomics/ACR-Position-Statements/Recommendations-for-ChestRadiography-and-CT-for-Suspected-COVID19-Infection.

12. Rubin GD, Haramati LB, Kanne JP, Schluger NW, Yim J-J, Anderson $D J$, et al. The role of chest imaging in patient management during the covid-19 pandemic: a multinational consensus statement from the Fleischner Society. Radiology. 2020;S0012-3692(20)30673-5. doi: 10.1016/j.chest.2020.04.003.

13. Defensoría del Pueblo del Perú. Informe de adjuntía Nº 15-AAE/ DP «El Derecho a la Salud: Servicios de emergencia en los establecimientos de salud y el acceso a medicamentos» [internet]. Lima: Defensoría del Pueblo; 2018 [citado 14 abril 2020]. Disponible en: https://www.defensoria.gob.pe/wp-content/uploads/2018/05/ Informe-de-Adjuntia-015-AAE-DP.pdf. 